\title{
Bystander effects of nitric oxide in anti-tumor photodynamic therapy
}

\author{
Jerzy Bazak ${ }^{1}$, Jonathan M. Fahey ${ }^{2}$, Katarzyna Wawak ${ }^{1}$, Witold Korytowski ${ }^{1,2}$, Albert W. Girotti ${ }^{2}$ \\ ${ }^{1}$ Department of Biophysics, Jagiellonian University, Krakow, 30-387, Poland \\ ${ }^{2}$ Department of Biochemistry, Medical College of Wisconsin, Milwaukee, WI, 53226, USA
}

Correspondence: Albert W. Girotti

E-mail: agirotti@mcw.edu

Received: January 23, 2017

Published online: February 27, 2017

\begin{abstract}
Ionizing radiation of specifically targeted cells in a given population is known to elicit pro-death or pro-survival responses in non-targeted bystander cells, which often make no physical contact with the targeted ones. We have recently demonstrated a similar phenomenon for non-ionizing photodynamic therapy (PDT), showing that prostate cancer cells subjected to targeted photodynamic stress stimulated growth and migration of non-stressed, non-contacting bystander cells. Diffusible nitric oxide (NO) generated by stress-upregulated inducible nitric oxide synthase (iNOS) was shown to play a dominant role in these responses. Moreover, target-derived NO stimulated iNOS/NO induction in bystanders, suggesting a NO-mediated feed-forward field effect driven by targeted cells surviving the photodynamic challenge. In this research highlight, we will review these findings and discuss their potential negative implications on clinical PDT outcomes and how these might be mitigated through pharmacologic use of select iNOS inhibitors.
\end{abstract}

Keywords: Bystander effects; photodynamic therapy; nitric oxide; iNOS; iNOS inhibitors

To cite this article: Jerzy Bazak, et al. Bystander effects of nitric oxide in anti-tumor photodynamic therapy. Can Cell Microenviron 2017; 4: e1511. doi: 10.14800/ccm.1511.

Copyright: (c) 2017 The Authors. Licensed under a Creative Commons Attribution 4.0 International License which allows users including authors of articles to copy and redistribute the material in any medium or format, in addition to remix, transform, and build upon the material for any purpose, even commercially, as long as the author and original source are properly cited or credited.

\section{Brief background on nitric oxide and its role in cancer}

Nitric oxide (NO) is a short-lived bioactive free radical that diffuses freely on its own and, like oxygen $\left(\mathrm{O}_{2}\right)$, tends to partition into hydrophobic regions of cells, e.g. cell membranes ${ }^{[1-3]}$. NO at low to moderate steady state levels, e.g. 50-500 nM, is known to play a key signaling role in the survival, proliferation, migration, and drug-resistance of many cancer cell types ${ }^{[3-5]}$. By contrast, NO at relatively high levels $(>1 \mu \mathrm{M})$, as generated by activated macrophages, for example, is cytotoxic, particularly after conversion to the strong oxidant peroxynitrite ${ }^{[1,2]}$. Thus, whether NO exhibits pro-tumor vs. anti-tumor properties depends to a great extent on the steady state levels that it can attain, which are typically quite low in transformed cells, as mentioned. While naturally occurring NO is known to be generated by three different nitric oxide synthases in mammalian cells (NOS1, NOS2, NOS3), NOS2 or inducible NOS (iNOS) is the isoform most closely associated with cancer initiation, progression, and persistence ${ }^{[4-8]}$. Depending on a number of variables, many cancer cells, including those derived from breast, prostate, colon, and brain tumors, express significant constitutive levels of iNOS/NO, which are often implicated in pro-survival/pro-growth signaling ${ }^{[4-6]}$. Knockdown of pre-existing iNOS using siRNA or shRNA methodology has been shown to attenuate growth and progression of various tumors in animal models ${ }^{[4-6]}$, thereby substantiating iNOS/NO's tumor-supporting role. iNOS level in resected tumors from cancer patients is now considered a reliable 
prognostic indicator, patients with highest levels given the poorest survival chances ${ }^{[9,10]}$. Although pre-existing iNOS may provide a survival/growth advantage in many tumors, the level of NO produced may still be limiting. One approach for examining this is to determine whether low dose NO from an exogenous chemical donor might further stimulate cancer cell growth or resistance to therapeutic agents/treatments. As one early example, we showed that the NO donor spermine-NONOate (SPNO) in sub-toxic doses dramatically increased the resistance of human breast cancer COH-BR1 cells to photodynamic cell killing ${ }^{[11]}$. Each of the following were shown to contribute to this response: (i) suppression of pro-apoptotic JNK and p38 $\alpha$ activation, (ii) suppression of pro-apoptotic Bax and Bid expression, and (iii) suppression of anti-apoptotic Bcl-xL down-regulation [11].

\section{Photodynamic therapy and how it is affected by NO}

Photodynamic therapy (PDT) is a unique, minimally invasive modality for solid tumors that involves a photosensitizing agent (PS), PS-exciting light in the far visible-to-near infrared range, and molecular oxygen ${ }^{[12-14]}$. Unlike chemotherapy or radiotherapy, PDT has few (if any) light-independent PS side effects, i.e. treatment is usually limited to the tumor site at which the PS accumulates and at which light is applied, often via fiber optic networks. PDT photodynamic action gives rise to singlet oxygen $\left({ }^{1} \mathrm{O}_{2}\right)$ and/or other cytotoxic reactive oxygen species ${ }^{[12-14]}$. In 1996, the first PS to receive FDA approval for certain tumors (e.g. esophageal) was Photofrin ${ }^{\circledR}$, an oligomeric form of hematoporphyrin ${ }^{[12]}$. Since then, it has been used for many other malignancies, including bladder, prostate, breast, and brain, some of which are resistant to other treatments ${ }^{[13,14]}$. The first in vivo studies to assess whether endogenous NO might affect PDT efficacy were carried out using Photofrin ${ }^{\circledR}$ as PS and mice bearing various syngeneic tumors ${ }^{[15.16]}$. The key finding was that PDT cure rate could be significantly improved by administering a NOS inhibitor immediately before ${ }^{[15]}$ or after ${ }^{[16]}$ PDT. Extent of improvement correlated with constitutive NO output, tumors with the highest output responding best to NOS inhibition ${ }^{[16]}$. The explanation offered was that dilation of tumor-supporting blood vessels was acting in opposition to PDT's vasoconstrictive effects, and NOS inhibition relieved this opposition ${ }^{[15,16]}$. A similar explanation was offered in a more recent study by other investigators ${ }^{[17]}$.

In addition to pre-existing PSs like Photofrin ${ }^{\circledR}$, pro-PSs have been developed, the most widely used one being 5-aminolevulinic acid (ALA). ALA enters tumor cells and is metabolized to protoporphyrin IX (PpIX), the active PS, via the heme biosynthetic pathway, the PpIX accumulating initially in mitochondria ${ }^{[18]}$. An important feature of ALA-PDT is that PpIX tends to accumulate preferentially in tumor cells rather than surrounding vascular cells ${ }^{[18,19]}$. Using this approach, we asked whether NO might antagonize PDT not only by vasodilation ${ }^{[15,16]}$, but also by enhancing stress resistance in tumor cells per se. Using human breast cancer COH-BR1 cells as an early test system (see above), we found that apoptotic photokilling after an ALA-PDT-like challenge was strongly inhibited by the exogenous NO donor SPNO ${ }^{[11]}$. Of greater importance vis-à-vis PDT efficacy was our subsequent discovery that photodynamic stress itself resulted in iNOS upregulation in these cells and that this increased their resistance to apoptotic photokilling ${ }^{[20,21]}$. We found, for example, that after a moderate ALA/light-imposed stress, iNOS mRNA was upregulated $~ 2$-fold and iNOS protein 3-4-fold, beginning $\sim 2 \mathrm{~h}$ after irradiation and persisting for at least another $24 \mathrm{~h}^{[20,21]}$. No changes were observed in dark (ALA-only) or light-only controls. nNOS and eNOS levels were barely detectable in COH-BR1 cells and did not change after ALA/light exposure. Using the fluorescent probe DAF-2DA, we found that the level of endogenous NO also increased after ALA/light and that targeting iNOS with specific inhibitors (1400W, GW274150) or intercepting NO with a well-known scavenger (cPTIO) strongly attenuated this increase ${ }^{[20]}$. Moreover, when any one of these agents was present during and after a photochallenge, the extent of caspase- 9 activation and apoptosis was substantially greater than in their absence. This was also observed when cells with shRNA-induced iNOS knockdown were challenged and in this case the effect was completely reversed by SPNO-derived NO [20]. Collectively, these findings indicated that NO from basal and/or photostress-induced iNOS was signaling for increased resistance as a stress adaptation. In examining this stress signaling from a mechanistic perspective, we found that Akt (PI3K-dependent protein kinase B) was rapidly phosphorylation-activated by ALA/light, and a PI3K inhibitor suppressed this along with transcription factor $\mathrm{NF}-\kappa \mathrm{B}$ activation and iNOS upregulation ${ }^{[21]}$. These and related findings suggested the following course of events: photostress activation of Akt, followed by NF- $\mathrm{KB}$ activation, iNOS transcription/translation, NO upregulation, and apoptosis resistance ${ }^{[21]}$. The signaling mechanism(s) by which NO elicits greater resistance are currently under investigation.

Of related interest was our discovery that cancer cells which could withstand a photodynamic challenge typically exhibited a more aggressive phenotype than unchallenged controls in terms of accelerated proliferation, migration, and invasion over at least a $48 \mathrm{~h}$ post-irradiation period. These 


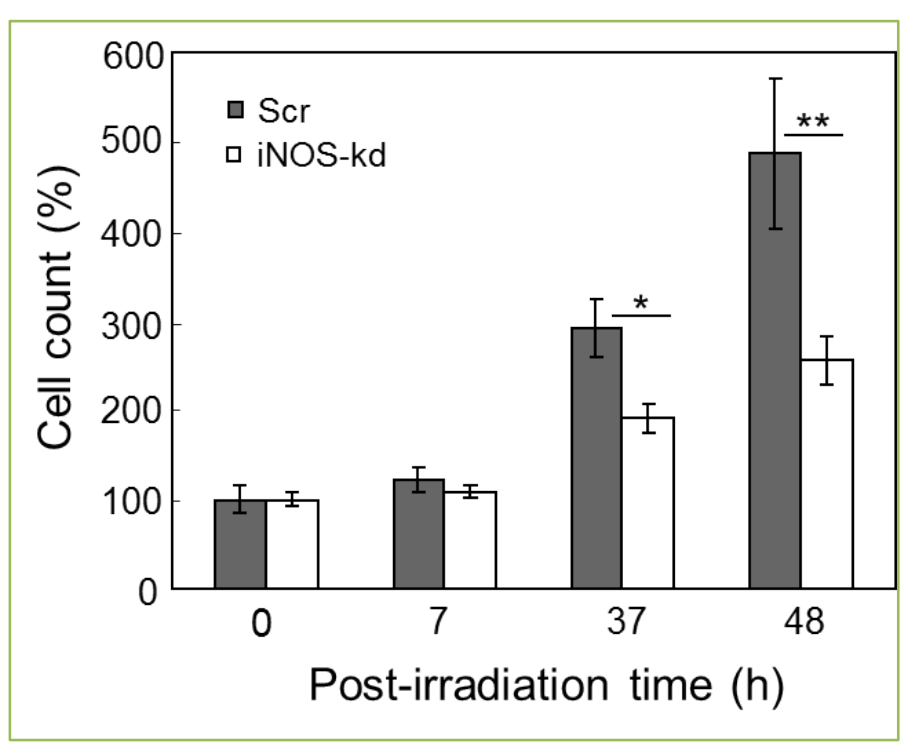

Figure 1. Effect of siRNA-induced iNOS knockdown in target cells on bystander cell proliferation. Prostate cancer PC3 cells were used, the targeted ones being dark-incubated with $1 \mathrm{mM} \mathrm{ALA}$ for $30 \mathrm{~min}$ in serum-free medium. After irradiation (light fluence $\sim 1$ $\mathrm{J} / \mathrm{cm}^{2}$ ), cells were washed free of ALA and switched to serum-containing medium, after which the separating rings were removed. Bystander cell proliferation was then monitored over $48 \mathrm{~h}$ of dark incubation, cell counts being obtained by Image-J analysis of photomicrographs. Data from iNOS-kd cells and scrambled vector controls (Scr) are compared; values are means \pm SEM $(n=12)$. ${ }^{*} \mathrm{P}<0.005$ vs. Scr; ${ }^{*} \mathrm{P}<0.002$ vs. Scr. Adapted from Figure 9 in Ref. 39.

responses were observed for prostate PC3 and DU145 cells ${ }^{[22,23]}$, breast MDA-MB-231 cells ${ }^{[24]}$, and glioblastoma U87 and U251 cells ${ }^{[25]}$. Similarly to photostress-induced resistance, more rapid proliferation and migration/invasion of surviving cells was strongly enhanced by $1400 \mathrm{~W}$ or cPTIO, indicating that iNOS/NO also played a major role in these responses ${ }^{[22-25]}$. It is important to note that PC3 cells consistently showed the lowest basal level of iNOS and the greatest upregulation (10-12-fold) after ALA/light. For these cells, therefore, most of the hyper-resistance and aggressiveness was due to stress-induced iNOS as opposed to pre-existing enzyme. Indeed, for all cells mentioned above, the effects described were at least partially due to iNOS upregulation. This was the first recognition that iNOS/NO induced by an oxidative stress-based anti-cancer therapy could antagonize the treatment outcome in multiple ways [22-25].

Some of the above findings were recently validated at the in vivo level by showing that (i) ALA-PDT regression of human breast MDA-MB-231 tumor xenografts in immunodeficient (SCID) mice was significantly enhanced by iNOS inhibitors (1400W, GW274150) and (ii) iNOS protein and NO (as nitrite) levels in these tumors were strongly elevated over several days after PDT treatment ${ }^{[24]}$. This was

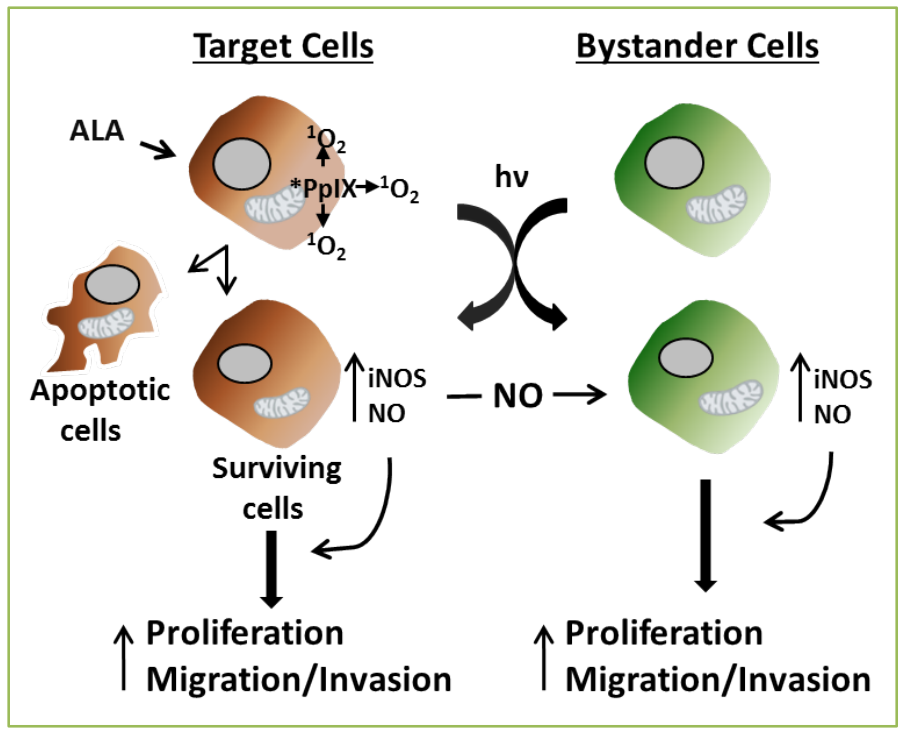

Figure 2. Schematic depicting bystander cell responses to NO generated by photodynamically stressed target cells. Both populations are irradiated, but only target cells sensitized with ALA-induced PpIX in mitochondria experience ${ }^{1} \mathrm{O}_{2}$-mediated oxidative stress leading to iNOS/NO upregulation. The NO increases target cell resistance to apoptosis and surviving cells, as well as NO-stimulated bystanders, grow and migrate more aggressively.

the first known evidence for iNOS/NO-induced resistance to PDT in an in vivo human tumor model.

Bystander effects in anti-cancer therapies: role of iNOS/NO

We recently discovered another NO-mediated response to PDT-induced oxidative stress, namely stimulation of non-stressed bystander cells. In general terms, a bystander effect occurs when cells exposed to a stress-inducing physical or chemical agent send signals to non- or minimally exposed counterparts (bystanders) ${ }^{[26]}$. Most of the research in this area has involved cancer-initiating vs. -suppressing ionizing radiation, which can elicit effects ranging from DNA damage, mutations, and apoptotic cell death to increased growth and migration ${ }^{[27-29]}$. Radiation-induced bystander effects can be transmitted via inter-cell gap-junctions or via the medium without physical contact between cells ${ }^{[29,30]}$. Although a variety of signaling effectors have been proposed, including cytokines, $\mathrm{H}_{2} \mathrm{O}_{2}$, and $\mathrm{NO}$, the latter has received greatest attention for contact-independent radiation-induced bystander effects ${ }^{[31-34]}$. NO from radiation-targeted cells has been reported to elicit bystander responses ranging from increased proliferation to defective homologous recombination repair, the latter promoting genetic instability and cell transformation ${ }^{[35]}$.

The possibility of bystander effects in conjunction with PDT has been recognized for several years ${ }^{[36-38]}$, but far less 
is known about this in mechanistic terms than for the radiation-induced counterpart. In addressing this question and the possible role of PDT-induced NO, we hypothesized that not all cells in a given tumor would be accessed uniformly by a PS (or pro-PS like ALA), largely due to irregularities in the supporting microvascular system. Moreover, not all tumor cells would be uniformly reached by subsequent irradiation. Consequently, cells experiencing the greatest photodynamic (PS/light) stress might send signals to non- or weakly-stressed bystanders. We used a novel approach to test this hypothesis and the possibility of NO acting as a signaling intermediate ${ }^{[39]}$. In initial studies, two populations of PC3 cells on a large $(13.5 \mathrm{~cm})$ culture dish were separated by 2-3 impermeable silicone rings; the larger population (target cells) was exposed to ALA/light, the other (bystander cells within rings) to light alone. At some interval after irradiation (typically $2 \mathrm{~h}$ ), the rings were removed, leaving a gap between both populations which was not breached during subsequent dark incubation. Both cell populations were then analyzed for various post-irradiation responses. As expected, target cells displayed a progressive and prolonged upregulation of Western-detected iNOS and DAF-2-detected NO ${ }^{[39]}$. More interestingly, we observed a slower, yet substantial induction of both iNOS and NO in bystander cells. These responses were strongly inhibited by cPTIO, indicating a significant dependency on NO initially generated in target cells. In addition to iNOS/NO upregulation, we observed a striking spurt in bystander proliferation and migration, which was forestalled by $1400 \mathrm{~W}$ and cPTIO, implying involvement of iNOS-derived NO ${ }^{[39]}$. When siRNA was used to knock down iNOS in target PC3 cells, the post-ALA/light bystander growth spurt was substantially diminished (Figure 1), confirming that target cell iNOS/NO played a major (in not exclusive) role in the enhanced aggressiveness ${ }^{[39]}$. Similar results were obtained in breast cancer COH-BR1 target/bystander experiments, suggesting general applicability. The lifetime of NO in aqueous media is very short, i.e. in the order of a few seconds ${ }^{[40]}$. Incubation with conditioned medium from ALA/light-targeted cells did not affect bystander growth rate, thereby ruling out any involvement of long-lived (relative to NO) effectors in the bystander responses. This includes relatively stable byproducts of NO such as nitrite $\left(\mathrm{NO}_{2}{ }^{-}\right)$and nitrous anhydride $\left(\mathrm{N}_{2} \mathrm{O}_{3}\right)$. Examination of possible effector proteins associated with greater growth/migration aggressiveness of bystander PC3 cells revealed a strong, yet transient, activation of the Akt and ERK1/2 kinases and an induction of cyclooxygenase-2 (COX-2), each response being cPTIO-inhibitable ${ }^{[39]}$. Figure 2 is a summary scheme showing the targeted photochallenge used in our experiments and its NO-mediated effects on bystander cells. In ongoing studies, several key issues are being addressed, including (i) mechanism(s) of bystander iNOS induction by NO from targeted cells, and (ii) mechanisms by which bystander growth and migration are stimulated by NO.

\section{Conclusions and perspectives}

We have presented solid evidence that pre-existing and/or overexpressed iNOS/NO can compromise a widely used anti-cancer therapy, PDT, and possibly stimulate disease progression if the extent of tumor eradication is not great enough. Sensitizer or pro-sensitizer uptake by cells in a given tumor is not expected to be uniform throughout, nor is light delivery during PDT. As a result, some cells will be more heavily stressed by PDT than others, some of which might be relatively unaffected bystanders. Using in vitro model systems, we have shown that photostressed target cells induce iNOS/NO for survival/expansion and that this is also elicited in bystander cells via diffusible NO ${ }^{[39]}$. It appears that a "relay-type" system is established whereby NO initially produced by targeted cells induces iNOS/NO in a bystander cell and that this is propagated through the bystander population. Similar propagation may occur in the targeted population. However, it was only through evaluation of separated cell populations that this phenomenon came to be realized in our studies. In the genre of radiation biology, this process has been described as a NO "feed-forward field effect" ${ }^{[34]}$. As anticipated for target cells that survive PDT, enhanced proliferative and migratory aggressiveness of bystander cells could potentially promote tumor growth and metastatic expansion. These negative side effects could be minimized through rational pharmacologic use of iNOS inhibitors as PDT adjuvants. Two promising candidates in this regard are L-NIL and GW274150, which have already been safely tested in clinical trials not related to cancer or $\operatorname{PDT}^{[41,42]}$.

\section{Conflicting interests}

The authors have declared that no conflict of interests exist.

\section{Acknowledgements}

The authors' research was supported by USPHS Grant CA70823 (to A.W.G.) from the National Cancer Institute, Grant NCN-2014/13/B/NZ3/00833 (to W.K.) from the Polish National Science Center, and Grant 5520347 from the Advancing a Healthier Wisconsin Research and Education Foundation (to A.W.G.). The authors are grateful to Neil Hogg for helpful discussions about generation and detection of NO in cancer cells. 
http://www.smartscitech.com/index.php/ccm

\section{Abbreviations}

NO: nitric oxide; iNOS/NOS2: inducible nitric oxide synthase; COX-2: cyclooxygenase-2; PDT: photodynamic therapy; ALA: 5-aminolevulinic acid; PpIX: protoporphyrin IX; NF-кB: nuclear factor kinase B; 1400W: $\mathrm{N}$-[3-(aminomethyl) benzyl]acetamidine; cPTIO: 2-(4-carboxyphenyl)-4,4,5,5-tetramethylimidazoline-1-oxyl3-oxide; DAF-2DA:4,5-diaminofluorescein diacetate; SPNO: spermine-NONOate; Akt: protein kinase B; ERK1/2: extracellular signal-regulated kinases-1/2.

\section{Author contributions}

J.B. carried out all the experiments, J.M.F and K.W. providing some advice and assistance along the way. W.K. and A.W.G. designed the studies. A.W.G. wrote the manuscript with input from W.K. All authors read and approved the final version of the manuscript.

\section{References}

1. Wink DA, Mitchell JB. Chemical biology of nitric oxide: insights into the regulatory, cytotoxic, and cytoprotective mechanisms of nitric oxide. Free Radic Biol Med 1998; 25:434-456.

2. Ridnour LA, Thomas DD, Donzelli S, Espey MG, Roberts DD, Wink DA, et al. The biphasic nature of nitric oxide responses in tumor biology. Antioxid Redox Signal 2006; 8:1329-1337.

3. Thomas DD, Ridnour LA, Isenberg JS, Flores-Santana W, Switzer $\mathrm{CH}$, Donzelli, et al. The chemical biology of nitric oxide: implications in cellular signaling. Free Radic Biol Med 2008; 45:18-31.

4. Heinecke JL, Ridnour LA, Cheng RY, Switzer CH, Lizardo MM, Khanna C, et al. Tumor microenvironment-based feed-forward regulation of NOS2 in breast cancer progression. Proc Natl Acad Sci U S A 2014; 111:6323-6328.

5. Thomas, DD, Heinecke JL, Ridnour LA, Cheng RY, Kesarwala $\mathrm{AH}$, Switzer $\mathrm{CH}$, et al. Signaling and stress: The redox landscape in NOS2 biology. Free Radic Biol Med 2015; 87:204-225.

6. Kostourou V, Cartwright JE, Johnstone AP, Boult JKR, Cullis ER, Whitley GSJ, et al. The role of tumour-derived iNOS in tumor progression and angiogenesis. Br J Cancer 2011; 104:83-90.

7. Bian K, Ghassemi F, Sotolongo A, Siu A, Shauger L, Kots A, et al. NOS-2 signaling and cancer therapy. IUMBM Life 2012; 64:678-683.

8. Vannini F, Kashfi K, Nath N. The dual role of iNOS in cancer. Redox Biol 2015; 6:334-343.

9. Glynn SA, Boersma BJ, Dorsey TH, Yi M, Yfantis HG, Ridnour LA et al. Increased NOS2 predicts poor survival in estrogen receptor-negative breast cancer patients. J Clin Invest 2010; 120:3843-3854.

10. Burke AJ, Sullivan FJ, Giles FJ, Glynn SA. The yin and yang of nitric oxide in cancer progression. Carcinogenesis 2013; 34:503-512.

11. Bhowmick R, Girotti AW. Signaling events in apoptotic photokilling of 5-aminolevulinic acid-treated tumor cells: inhibitory effects of nitric oxide. Free Radic Biol Med 2009; 47:731-740.

12. Dougherty TJ, Gomer CJ, Henderson BW, Jori G, Kessel D, Korbelik M et al. Photodynamic Therapy. J Natl Cancer Inst 1998; 90:889-905

13. Agostinis P, Berg K, Cengel KA, Foster TH, Girotti AW, S.O. Gollnick, et al. Photodynamic therapy of cancer: an update. CA Cancer J Clin 2011; 61:250-281.

14. L. Benov, Photodynamic therapy: current status and future directions. Med Princ Pract 2015; 24:14-28.

15. Henderson BW, Sitnik-Busch TM, Vaughan LA. Potentiation of photodynamic therapy antitumor activity in mice by nitric oxide synthase inhibition is fluence rate dependent. Photochem Photobiol 1999; 70:64-71.

16. Korbelik M, Parkins CS, Shibuya H, Cecic I, Stratford RML, Chaplin DL. Nitric oxide production by tumor tissue: impact on the response to photodynamic therapy. $\mathrm{Br} \mathrm{J}$ Cancer 2000; 82:1835-1843.

17. Reeves KJ, Reed MWR, Brown NJ. Is nitric oxide important in photodynamic therapy? J Photochem Photobiol B. Biology. 2009; 95:141-147.

18. Peng Q, Berg K, Moan J, Kongshaug M, Nesland JM. 5-Aminolevulinic acid-based photodynamic therapy: principles and experimental research. Photochem Photobiol 1997; 65:235-251.

19. Dorward AM, Francher KS, Duffy TM, Beamer WG, Walt H. Early neoplastic and metastatic mammary tumours of transgenic mice detected by 5-aminolevulinic acid-stimulated protoporphyrin IX accumulation. Br J Cancer 2005; 93:1137-1143.

20. Bhowmick R, Girotti AW. Rapid upregulation of cytoprotective nitric oxide in breast tumor cells subjected to a photodynamic therapy-like oxidative challenge. Photochem Photobiol 2011; 87:378-386.

21. Bhowmick R, Girotti AW. Cytoprotective signaling associated with nitric oxide upregulation in tumor cells subjected to photodynamic therapy-like oxidative stress. Free Radic Biol Med 2013; 57:39-48.

22. Bhowmick R, Girotti AW. Pro-survival and pro-growth effects of stress-induced nitric oxide in a prostate cancer photodynamic therapy model. Cancer Lett 2014; 343:115-122.

23. Fahey JM, Girotti AW. Accelerated migration and invasion of prostate cancer cells after a photodynamic therapy-like challenge: role of nitric oxide. Nitric Oxide 2015; 49:47-55.

24. Fahey JM, Girotti AW. Nitric oxide-mediated resistance to photodynamic therapy in a human breast tumor xenograft: improved outcome with NOS2 inhibitors. Nitric Oxide 2017; 62:52-61.

25. Fahey JM, Emmer JV, Korytowski W, Hogg N, Girotti AW. Antagonistic effects of endogenous nitric oxide in a glioblastoma photodynamic therapy model. Photochem Photobiol 2016; 92:842-853.

26. Alexandre J, Hu Y, Lu W, Pelicano H, Huang P. Novel action of paclitaxel against cancer cells: bystander effect mediated by reactive oxygen species. Cancer Res 2007; 67:3512-3517.

27. Nagasawa H, Little JB. Induction of sister chromatid exchanges by 
http://www.smartscitech.com/index.php/ccm

extremely low doses of alpha-particles. Cancer Res 1992; 52:6394-6396.

28. Azzam EI, de Toledo SM, Little JB. Stress signaling from irradiated to non-irradiated cells, Curr Cancer Drug Targets 2006; 4:53-64.

29. Hei TK, Zhou H, Chai Y, Ponnaiya B, Ivanov VN. Radiation-induced non-targeted response: mechanism and potential clinical implications. Curr Mol Pharmacol 2011; 4:96-105.

30. Baskar R. Emerging role of radiation-induced bystander effects: cell communications and carcinogenesis. Genome Integr 2010; $1: 13$

31. Matsumoto H, Hayashi S, Hatashita M, Ohnishi K, Shioura H, Ohtsubo $\mathrm{T}$ et al. Induction of radioresistance by a nitric oxide-mediated bystander effect. Radiat Res 2001; 155:387-396.

32. Matsumoto H. Takahashi A, Ohnishi T. Nitric oxide radicals choreograph a radioadaptive response. Cancer Res 2007; 67:8574-8579.

33. Han $\mathrm{W}$, Chen $\mathrm{S}, \mathrm{Yu} \mathrm{KN}, \mathrm{Wu}$ L. Nitric oxide-mediated DNA double strand breaks induced in proliferating bystander cells after alpha-particle irradiation. Mutat Res 2010; 684:81-89.

34. Yakovlev VA. Role of nitric oxide in the radiation-induced bystander effect. Redox Biology 2015; 6:396-400.

35. Yakovlev VA. Nitric oxide-dependent downregulation of BRCA1 expression promotes genetic instability. Cancer Res 2012;
73:706-715.

36. Dahle J, Bagdonas S, Kaalhus O, Olsen G, Steen HB, Moan J. The bystander effect in photodynamic inactivation of cells. Biochim Biophys Acta 2000; 1475:273-280.

37. Chakraborty A, Held KD, Prise KM, Liber HL, Redmond RW. Bystander effects induced by diffusing mediators after phododynamic stress. Radiat Res 2009; 172:74-81.

38. Rubio N, Rajadurai A, Held KD, Prise KM, Liber HL, Redmond RW. Real-time imaging of novel spatial and temporal responses to photodynamic stress. Free Radic Biol Med 2009; 47:283-290.

39. Bazak J, Fahey JM, Wawak K, Korytowski W, Girotti AW. Enhanced aggressiveness of bystander cells in an anti-tumor photodynamic therapy model: role of nitric oxide produced by targeted cells. Free Radic Biol Med 2017; 102:111-121.

40. Thomas DD, Liu X, Kantrow SP, Lancaster JR. The biological lifetime of nitric oxide: implications for the perivascular dynamics of NO and O2. Proc Natl Acad Sci USA. 2001; 98:355-360.

41. Hansel TT. Kharitonov SA, Donnelly LE, Erin EM, Currie MG, Moore WM et al. A selective inhibitor of inducible nitric oxide synthase inhibits exhaled breath nitric oxide in healthy volunteers and asthmatics. FASEB J. 2003; 17:1298-1317.

42. Singh D, Richards D, Knowles RG, Schwartz S, Woodcock A, Langley $\mathrm{S}$ et al. Selective inducible nitric oxide synthase inhibition has no effect on allergen challenge in asthma. Am J Respir Crit Care Med. 2007; 176:988-993. 